\title{
Effects of CIK on hypoxia inducible factor-1 $\alpha$ and T-cell subsets on colon 26 cancer xenograft mice
}

\author{
HONGZHEN ZHANG ${ }^{1}$, MINGLI GUO ${ }^{2}, \mathrm{HONGYAO} \mathrm{CHEN}^{2}$, YING ZHANG $^{3}$ and LI YA HE ${ }^{1}$ \\ Departments of ${ }^{1}$ Fifth Oncology, ${ }^{2}$ Otorhinolaryngology and ${ }^{3}$ Human Resources, \\ Hebei People's Hospital, Shijiazhuang, Hebei 050051, P.R. China
}

Received November 24, 2015; Accepted January 7, 2016

DOI: $10.3892 / \mathrm{ol} .2016 .4081$

\begin{abstract}
Colorectal cancer is a common malignancy of the digestive tract with a high mortality rate. However, current treatment approaches such as radiotherapy and chemotherapy are ineffective. Thus, it is imperative to identify ways to treat recurrence and metastasis. The aim of the present study was to investigate the effects of cytokine-induced killer (CIK) cells on the hypoxia microenvironment and immune function in colon 26 cancer xenograft mice. A murine model of colon 26 carcinoma tumors were divided into CIK, normal saline (NS) and control groups. Hypoxia inducible factor-1 $\alpha$ (HIF-1 $\alpha)$ mRNA in tumor tissue and the small intestine of mice was detected by FQ-PCR. The percentage of the CD4 ${ }^{+}$, $\mathrm{CD}^{+}$and $\mathrm{CD}^{+} / \mathrm{CD}^{+}$ratio in the spleen of mice was detected by flow cytometry. The tumor volume in the CIK group was smaller than that in the NS group and the difference was not significant $(\mathrm{P}>0.05)$. HIF-1 $\alpha$ gene expression was present in the tumor tissue and small intestine. HIF-l $\alpha$ gene expression in tumor tissue was significantly higher than that in the small intestine $(\mathrm{P}<0.05)$, and lower in tumor tissue of the CIK group compared to the NS group $(\mathrm{P}<0.05)$ of xenograft mice. However, no HIF-1 $\alpha$ expression was observed in the small intestine of healthy control mice. $\mathrm{CD} 4^{+} \mathrm{T}$-cell percentage and $\mathrm{CD}^{+} / \mathrm{CD}^{+}$ratio in the spleen of xenograft mice was significantly lower than that of normal mice $(\mathrm{P}<0.05)$. Compared to the NS group, the $\mathrm{CD}^{+}{ }^{+} \mathrm{T}$-cell percentage was higher, whereas the $\mathrm{CD}^{+} \mathrm{T}$-cell percentage was lower in the CIK group $(\mathrm{P}<0.05)$. In conclusion, HIF-1 $\alpha$ gene expression was present in the tumor tissue and small intestine. The immune function of colon 26 transplanted in tumor mice was decreased. Additionally, CIK improved the microenvironment of tumor hypoxia and promoted immune reconstitution.
\end{abstract}

Correspondence to: Dr Hongzhen Zhang, Department of Fifth Oncology, Hebei People's Hospital, 348 Heping West Street, Shijiazhuang, Hebei 050051, P.R. China

E-mail:nm661z@163.com

Key words: colon 26 cells, colon cancer, microenvironment, hypoxia inducible factor- $1 \alpha$, T-cell subsets, cytokine-induced killer cells

\section{Introduction}

Colorectal cancer is a common malignant tumor of the digestive tract. It is the third most common cancer diagnosed in men and the second most common in women. More cases of male mortality compared to female mortality have been reported (1). The age-standardized incidence is $44 \%$ higher in males $(20.6$ vs. 14.3 per 100,000 individuals) and that of the mortality rate is $45 \%$ higher in males (10.0 vs. 6.9 per 100,000) (1). Surgery, radiotherapy and chemotherapy are therefore ineffective against the recurrence and metastasis of colorectal cancer. Cytokine-induced killer (CIK) is the newest tumor adoptive immunotherapy method at present (2-4). However, few studies have been performed regarding the association of CIK and tumor hypoxia and T-cell subsets.

The aim of the present study was to investigate the effect of CIK on HIF-1 $\alpha$, hypoxia microenvironment and immune function in tumor-burdened mice.

\section{Materials and methods}

Experimental animals and tumor cell line. Healthy male Kunming mice (6- to 8-weeks old, weight 20-24 g; certificate no. 902078) were purchased from the Experimental Animal Center of Hebei Medical University. The mice were housed in an environment with a temperature of $18-22^{\circ} \mathrm{C}$ and humidity of $50-60 \%$, and had access to food and water ad libitum. The colon 26 cancer cell strain was purchased from the Research Center of Hebei Medical University Fourth Hospital.

Key reagents. The reagents used in the present study were: genic recombination interleukin (IL)-1 (PeproTech, Rocky Hill, NJ, USA), IL-2, interferon- $\gamma$ (IFN- $\gamma$ ) (Beijing Sihuan Bio-engineering Products Factory, Beijing, China), anti-mouse antibody PE-CD4 mAb and FITC-CD8 mAb (eBioscience, Inc., San Diego, CA, USA), HIF-1 kit (R\&D Systems, Inc., Minneapolis, MN, USA) were used. Human lymphocyte separation medium (Tianjin Virtue Asm Pacific Technology Ltd., Tianjin, China), and mouse anti-human CD3Mab antibody (Laboratory of Immunology in Health Science Center of Peking University, Beijing, China) were also used.

Peripheral blood separation and the induction of CIK effect on cells (5). Peripheral blood $(50 \mathrm{ml})$ was taken in vacutainers 
with heparin from healthy adults. Lymphocyte apheresis collections were used in the blood sampling machine at $1,007 \mathrm{~g} / \mathrm{ml}$ Ficoll and were separated using density gradient centrifugation at 2,500 rpm for $30 \mathrm{~min}$ and peripheral blood mononuclear cells (PBMC). The RPMI-1640 liquid transfer of PBMC was used at the starting density of $5 \times 10^{6} / \mathrm{ml}$. IFN- $\gamma$ $\left(1 \times 10^{3} \mathrm{U} / \mathrm{ml}\right)$ was added and set at $37^{\circ} \mathrm{C}$ with $5 \% \mathrm{CO}_{2}$ in a culture incubator. After $24 \mathrm{~h} 50 \mathrm{U} / \mathrm{ml}$ of CD3 monoclonal antibody and $500 \mathrm{U} / \mathrm{ml}$ of IL-2 were added. Subsequently, IL-2 at a concentration of $500 \mathrm{U} / \mathrm{ml}$ in fresh medium was added every 2-3 days. The cells were then cultured for 14 days as effector cells.

Effector cells inhibit tumor growth in tumor-bearing mice. The second generation of cultured colon 26 cells in the logarithmic growth phase was used for the experiment. After 8 days of feeding, the mice were inoculated with tumor cells. An axillary subcutaneous injection of $1 \mathrm{ml}$ cell suspension (containing $\sim 2 \times 10^{6} / \mathrm{ml}$ tumor cells) was injected into the mice. The inoculation site appeared to be a hard nodule identified as a tumor. When the average volume of the transplanted tumor in mice was $\sim 0.30 \mathrm{~cm}^{3}$, modeling was successful. Six mice were randomly selected as the health contrast group (group A). After the successful modeling, EXCEL software (Excel list v1.0.909 randomized tools) was used to divide mice with transplanted tumors into two groups of 6 mice each. The normal saline (NS) contrast group (group B) was infused intravenously in tail with $0.2 \mathrm{ml}$ physiological saline on days 0 and 3 . The colon cancer CIK treatment group (group C) was infused intravenously in tail with CIK cells $\left(4 \times 10^{7} / 0.2 \mathrm{ml}\right)$ on days 0 and 3 . On day 12 of treatment intervention, the mice were sacrificed and subcutaneous transplantation tumor length was measured using vernier caliper $(a, b)$ and the tumor volume was calculated. Spleen and colon tumor tissue were removed, and stored in liquid nitrogen at $209.86^{\circ} \mathrm{C}$ below zero.

The tumor volume $\{\mathrm{RV}[\mathrm{V}(\mathrm{mms})=\mathrm{axb} 2 / 2]\}$ and relative tumor volume [RTV (V11/V1) V0 is the tumor volume measured on day 0 and V11 the tumor volume measured on day 11] were calculated as per the general standard formula.

Flow cytometry (FCM) detection of $\mathrm{CD}^{+}$vs. $\mathrm{CD}^{+}$expression in mice. The mice were sacrificed and the spleen was removed, sterilized, sheared, and pulverized in 200 mesh steel. The spleen was washed with incomplete RPMI-1640 culture solution, and suspended in ice. Spleen cell suspensions were gradually placed in the prepared lymphocyte separation liquid (accounting for 1,080 of the Ficoll-Hypaque) to divide and separate lymphocytes. Cell suspension was centrifuged at 2,000 rpm for $20 \mathrm{~min}$, and the second layer of opaque low-density cells was extracted, washed $(2 \mathrm{X})$ in incomplete culture fluid and centrifuged at 1,000 rpm to obtain the cell number of $1 \times 10^{6} / \mathrm{ml}$ in cell suspension. The cell suspension $(1 \mathrm{ml})$ was added into a tube. PE-labeled antimouse CD4 $\mathrm{mAb}$ and FITC-labeled CD8 mAb $(1: 2,000)$ were also added. After $30 \mathrm{~min}, 2 \mathrm{ml}$ red cell lysate was added and incubated for $10 \mathrm{~min}$. Phosphate-buffered saline $(2 \mathrm{ml})$ was added to the cell suspension and centrifuged (2X) at 1,000 rpm for $5 \mathrm{~min}$, and the supernatant was discarded. The ratio of each subpopulation of cells among $1 \times 10^{6}$ cells was detected by FCM (FC 500; Beckman Coulter, Miami, FL, USA).
Determination of hypoxia inducible factor-1 $\alpha(H I F-1 \alpha)$. HIF-1 $\alpha$ mRNA expression was evaluated by reverse transcription-quantitative polymerase chain in tumor body and small intestine of the tumor-transplanted group and the health contrast group of mice.

Statistical analysis. SPSS 16.0 (SPSS, Inc., Chicago, IL, USA) software was used to process the data. Quantitative data were presented as mean \pm standard deviation. The t-test was used for comparison of the two groups. $\mathrm{P}<0.05$ was considered to indicate a statistically significant difference.

\section{Results}

HIF-1 $\alpha$ gene expression and changes in splenic T lymphocytes. HIF-1 $\alpha$ gene was expressed in the transplanted tumor and small intestine of mice. $H I F-1 \alpha$ gene expression in tumor tissues was significantly higher than that in the small intestine $(\mathrm{P}<0.05)$. As shown in Tables I and II, the percentage of $\mathrm{CD}^{+} \mathrm{T}$ cells and the $\mathrm{CD} 4^{+} / \mathrm{CD}^{+} \mathrm{T}$ ratio in spleen tissue of mice with transplanted tumor was significantly lower than that of healthy mice $(\mathrm{P}<0.05)$.

Effect of CIK on transplanted tumor volume. Transplanted tumors gradually increased in size subcutaneously in mice. Local tumor nodular growth led to the tumor began to be touched, 4-5 days after subcutaneous inoculation of the cells. For days 1-7, tumor growth was essentially the same, but for days $8-17$, tumor growth in the physiological saline group was significantly more rapid than the other groups. The CIK group had the most retarded tumor growth compared to the NS group. The tumor volume was reduced in the CIK group but was not statistically significant $(\mathrm{P}>0.05)$ (Table III).

Effect of CIK on the HIF-1 $\alpha$ gene expression in mice tumor tissue. Fluorescent quantitative analysis showed that compared to the saline group, $H I F-l \alpha$ gene expression was decreased in the tumor tissue of the CIK group, although with no statistical significance $(\mathrm{P}>0.05)$ (Table III).

Effect of CIK on transplanted spleen tumor T lymphocytes in mice. Compared to the health contrast group, the percentage of $\mathrm{CD}^{+} \mathrm{T}$ cells in tumor-transplanted mice decreased, and for the $\mathrm{CD}^{+} / \mathrm{CD}^{+}$inversion, the ratio of $<1$, was statistically significant $(\mathrm{P}<0.05)$. Compared to the NS group, the percentage of $\mathrm{CD}^{+} \mathrm{T}$ cells and $\mathrm{CD} 4 / \mathrm{CD} 8$ of the CIK group were increased, and the result was statistically significant $(\mathrm{P}<0.05)$ (Table II).

\section{Discussion}

Colon cancer is a common malignant tumor of the digestive tract, and ranks third among gastric intestinal tumors. The incidence of colorectal cancer in China has been on the increase at a rate of $4 \%$ annually (6). Among patients with stage IV colorectal cancer, the 5-year survival rate is only $8.1 \%$, with poor side-effects and adverse reaction of radiotherapy and chemotherapy. The immune system is also suppressed when killing tumor cells. Therefore, it is crucial to identify an effective treatment for advanced colorectal cancer. 
Table I. HIF-1a gene expression in tumor and intestinal tissue of mice.

\begin{tabular}{lccc}
\hline HIF-1 $\alpha$ & NC & NS & CIK \\
\hline Tumor & - & $25.847 \pm 1.303^{\mathrm{a}}$ & $24.790 \pm 0.42^{\mathrm{a}}$ \\
Small intestine & - & $4.131 \pm 1.1603^{\mathrm{b}}$ & $4.113 \pm 0.930$ \\
\hline
\end{tabular}

${ }^{\mathrm{a}} \mathrm{P}<0.05$, compared to small intestine; ${ }^{\mathrm{b}} \mathrm{P}<0.05$, compared to health contrast group; ${ }^{\mathrm{C}} \mathrm{P}<0.05$, compared to $\mathrm{CIK}$ group. $\mathrm{NC}$, normal control; NS, normal saline; CIK, cytokine-induced killer; HIF-1 $\alpha$, hypoxia inducible factor- $1 \alpha$.

Table II. Expression of spleen T lymphocytes in various groups of mice.

\begin{tabular}{lrrc}
$\begin{array}{l}\text { T-lymphocyte } \\
\text { subsets }\end{array}$ & NC & NS & CIK \\
\hline CD4, \% & $35.43 \pm 2.70$ & $15.05 \pm 2.68^{\mathrm{a}}$ & $27.85 \pm 4.82^{\mathrm{a}, \mathrm{b}}$ \\
$\mathrm{CD} 8, \%$ & $20.88 \pm 2.34$ & $18.30 \pm 4.00$ & $17.93 \pm 2.49$ \\
$\mathrm{CD} 4 / \mathrm{CD} 8$ & $1.72 \pm 0.27$ & $0.85 \pm 0.20^{\mathrm{a}}$ & $1.57 \pm 0.34^{\mathrm{a}, \mathrm{b}}$ \\
\hline
\end{tabular}

${ }^{\mathrm{a}} \mathrm{P}<0.05$, compared to health contrast group; ${ }^{\mathrm{b}} \mathrm{P}<0.05$, compared to saline group. NC, normal control; NS, normal saline; CIK, cytokineinduced killer.

Table III. Changes in transplanted tumor volume in mice.

\begin{tabular}{lcccccc}
\hline & \multicolumn{2}{c}{$\begin{array}{c}\text { No. } \\
\text { of mice }\end{array}$} & & \multicolumn{3}{c}{ TV $\left(\mathrm{cm}^{3}\right)$} \\
\cline { 2 - 3 } Group & D0 & D11 & & D0 & D11 & RTV \\
\hline NS & 6 & 6 & & $0.327 \pm 0.072$ & $2.034 \pm 0.755$ & $6.36 \pm 2.28$ \\
CIK & 6 & 6 & & $0.344 \pm 0.020^{\mathrm{a}}$ & $1.969 \pm 0.683^{\mathrm{a}}$ & $6.25 \pm 1.30$ \\
\hline
\end{tabular}

${ }^{\mathrm{a}} \mathrm{P}<0.05$, compared to saline group. NS, normal saline; CIK, cytokineinduced killer; TV, tumor volume; RTV, relative tumor volume.

The immune system can play a monitoring role in the identification and elimination of new antigen expression of 'dissident' ingredients or mutated cells, and an important role in the anti-tumor mechanism. Biological immunotherapy enhances the antitumor immunity of the tumor microenvironment by stimulating or adjusting the immune function to kill tumor cells. CIK is currently known as a biological treatment affecting cells with strong tumor killing activity (7). In vitro stimulation of human PBMC by various cytokines (IL-2, IL-1, IFN- $\gamma$ and CD3 McAb) can produce a group of heterogeneous cells, which can directly or indirectly regulate the immune function of host. CIK has been shown to play a strong antitumor effect on colon cancer therapy (8). Immune dysfunction is closely associated with the occurrence of malignant tumor (8). Low immune function leads to 'immune drift', involving the decreased cellular immunity with humoral immunity enhancement, and the anti-tumor immunity being critically affected. T-cell subsets are important factors for immune defense, and are important in anti-tumor immunity. $\mathrm{T}$ cells primarily consist of two subsets of the helper T-cell (Th) $\mathrm{CD}^{+}$and suppressor $\mathrm{T}$-cell $\mathrm{CD} 8^{+}$, which maintain the immune balance of the body. $\mathrm{CD} 4^{+} \mathrm{T}$ cells can regulate the immune reaction activity, assist B cells to produce antibodies, cytokine secretion, promote $\mathrm{CD} 8^{+} \mathrm{T}$ cell activation, and produce cytotoxic $\mathrm{T}$ lymphocytes cells, while $\mathrm{CD} 8^{+}$cells have an immunosuppressive and cytotoxic effect (9). A decrease of $\mathrm{CD}^{+}$or increase in $\mathrm{CD}^{+}$cells creates an imbalance, resulting in immune function defects. Previous findings have shown that the state of T-cell subsets of patients with tumor is abnormal and within the ratio. A reduction in the ratio of $\mathrm{CD} 4^{+} / \mathrm{CD}^{+}$is associated with the extent of lesions, suggesting that the cellular immune functions of the patients are at an inhibitory state with a reduction in the recognition and killing ability of mutant cells, thus facilitating tumor growth and metastasis. Generally, $\mathrm{CD}^{+}$cells in patients with malignant tumor (Th) show a decreased $\mathrm{CD} 4^{+} / \mathrm{CD}^{+}$ratio, and even reverse performance whereby the immune surveillance function decreases and the body is in a state of immune suppression (9). Therefore, detection of the distribution of T-cell subsets reflects anti-tumor immunological functions. The results of the present study show that compared to the health contrast group, $\mathrm{CD}^{+}$levels were significantly decreased with $\mathrm{CD} 4^{+} / \mathrm{CD} 8^{+}$inversion and the ratio of $<1$ in mice with transplanted tumor. As reported earlier, we also observed that the distribution of T-cell subsets in mice was arranged in a disorderly manner with immune suppression (10). Ling et al (11) reported that CIK cells can improve the immune function of $\mathrm{T}$ cells, and are conducive to the control of tumor metastasis and recurrence. In the current study, we observed that following tumor transplantation and treatment with $\mathrm{CIK}, \mathrm{CD} 4^{+} \mathrm{T}$ cells and $\mathrm{CD} 4^{+} / \mathrm{CD}^{+}$ were increased, indicating that CIK cell therapy is capable of improving immune function in mice with transplanted tumor, conducive to enhancing T-cell recognition of tumor cells, and exerting antitumor effects, which is consistent with the reported literature (11).

Hypoxia is an important characteristic of solid tumor, and HIF- $1 \alpha$ is a key factor of tumor hypoxia response. It is an upstream transcription regulating protein for the regulation of tumor angiogenesis, energy metabolism, cell proliferation, metastasis and invasion associated with tumor occurrence, development, recurrence, chemotherapy resistance as well as multidrug resistance (12). HIF-1a is overexpressed in most tumors, including colorectal cancer with an overexpression of $>90 \%$. The results of the current study show $H I F-1 \alpha$ gene expression in tumor body and small intestine. In tumor body, the expression level was higher than that in the small intestine, although no expression was observed in the small intestine of healthy mice, which is consistent with earlier reports (12).

The tumor microenvironment is an environment where the tumor is located in the developmental process, including tumor cells, stromal cells, microvascular and tissue fluid and a small amount of infiltrating cells, such as dendritic cells and macrophages (13). The tumor microenvironment is also the execution site for antitumor immune effect stage (13). However, low $\mathrm{O}_{2}$, low $\mathrm{pH}$, and low nutritional status of the tumor microenvironment is insufficient to provide the necessary $\mathrm{O}_{2}$ and energy 
for the cellular immune response, which is not conducive to the contact reaction of immune cells and attacking targets, resulting in tumor immune suppression (14). The tumor microenvironment is equivalent to a chronic inflammatory environment and hypoxic tumor cells and necrotic regional cell debris release high levels of chemokines with activation of the nuclear factor- $\kappa \mathrm{B}$ pathway and recruitment of immune cells to hypoxia (15). In the hypoxic microenvironment, immune cells targeted as cancer cells cannot entirely activate their killing effect allowing the tumor to elude the immune response. Thus, the effective implementation of the antitumor function cannot be carried out. Tumor cells exposed to hypoxic environment are likely to develop into inferior genetic stability and more aggressive malignant cells, and become resistant to the treatment (16). Therefore, the downregulation of $H I F-1 \alpha$ gene expression can prevent the hypoxia-induced reaction required for tumor growth, thereby inhibiting tumor growth. This finding confirmed that the HIF-l $\alpha$ gene expression in the tumor body of mice decreased following treatment with CIK. The tumor volume in mice of the CIK group was smaller than that in the saline group (17). Thus CIK cells as immunocompetent cells induced in vitro amplification resulting in, not only enhancement of the immune function, but also the interruption of the immune suppression state by improvement of the hypoxia tumor microenvironment to further enhance immune function and play an antitumor effect.

Based on the results, the breakthrough and hotspot of colorectal cancer treatment is identified by two aspects: the improvement of the tumor hypoxic microenvironment where malignant cells are located, and the enhancement of the body's own immune system. Thus, based on the two aspects, we concurrently detected T-cell subsets of spleen tissue of mice and employed the immune effect. Immune suppression and $H I F-1 \alpha$ gene expression are cytokines associated with inflammation as well as immune suppression and tumor microenvironment, serving as a breakthrough point to discuss the effect of CIK on colon cancer transplantation mice. However, in the tumor hypoxia microenvironment, the mutual effect of HIF- $1 \alpha$ and the immune function remain to be elucidated in future studies.

\section{References}

1. Clarke N, Sharp L, Osborne A and Kearney PM: Comparison of uptake of colorectal cancer screening based on fecal immunochemical testing (FIT) in males and females: a systematic review and meta-analysis. Cancer Epidemiol Biomarkers Prev 24: 39-47, 2015
2. Zoll B, Lefterova P, Ebert O, Huhn D, Von Ruecker A and Schmidt-Wolf IG: Modulation of cell surface markers on NK-like T lymphocytes by using IL-2, IL-7 or IL-12 in vitro stimulation. Cytokine 12: 1385-1390, 2000.

3. Wei XC, Zhai XH, Han XR, Yang DD and Zhao WL: Biological activity of DC-CIK cells and its effect against leukemia cells in vitro. Zhongguo Shi Yan Xue Ye Xue Za Zhi 16: 1150-1153, 2008.

4. Motzer RJ and Russo P: Systemic therapy for renal cell carcinoma. J Urol 163: 408-417, 2000.

5. Jemal A, Siegel R, Ward E, Murray T, Xu J, Smigal C and Thun MJ: Cancer statistics, 2006. CA Cancer J Clin 56: 106-130, 2006.

6. Jiang Z, Li C, Qiu X, Xu Y, Wang X and Cai S: Analysis of factors associated with prognosis after colorectal cancer resection in 174 Chinese elderly patients. J Gastrointest Surg 15: 644-651, 2011.

7. Mellman I, Coukos G and Dranoff G: Cancer immunotherapy comes of age. Nature 480: 480-489, 2011.

8. Franceschetti M, Pievani A, Borleri G, Vago L, Fleischhauer K, Golay $\mathrm{J}$ and Introna M: Cytokine-induced killer cells are terminally differentiated activated CD8 cytotoxic T-EMRA lymphocytes. Exp Hematol 37: 616-628.e2, 2009.

9. Schlimper C, Hombach AA, Abken H and Schmidt-Wolf IG: Improved activation toward primary colorectal cancer cells by antigen-specific targeting autologous cytokine-induced killer cells. Clin Dev Immunol 2012: 238924, 2012.

10. Devarajan P and Chen Z: Autoimmune effector memory T cells: the bad and the good. Immunol Res 57: 12-22, 2013.

11. Ling KL, Pratap SE, Bates GJ, Singh B, Mortensen NJ, George BD, Warren BF, Piris J, Roncador G, Fox SB, et al: Increased frequency of regulatory $\mathrm{T}$ cells in peripheral blood and tumour infiltrating lymphocytes in colorectal cancer patients. Cancer Immun 7: 7, 2007

12. Seeber LMS, Horrée N, Vooijs MAGG, Heintz APM, van der Wall E, Verheijen RHM and van Diest PJ: The role of hypoxia inducible factor-1alpha in gynecological cancer. Crit Rev Oncol Hematol 78: 173-184, 2011.

13. Klemm F and Joyce JA: Microenvironmental regulation of therapeutic response in cancer. Trends Cell Biol 25: 198-213, 2015.

14. Hurwitz AA and Watkins SK: Immune suppression in the tumor microenvironment: a role for dendritic cell-mediated tolerization of $\mathrm{T}$ cells. Cancer Immunol Immunother 61: 289-293, 2012.

15. Mancino A and Lawrence T: Nuclear factor-kappaB and tumor-associated macrophages. Clin Cancer Res 16: 784-789, 2010.

16. Erler JT, Bennewith KL, Nicolau M, Dornhöfer N, Kong C, Le QT, Chi JT, Jeffrey SS and Giaccia AJ: Lysyl oxidase is essential for hy poxia-induced metastasis. Nature 440: 1222-1226, 2006.

17. Rofstad EK, Mathiesen B, Kindem K and Galappathi K: Acidic extracellular $\mathrm{pH}$ promotes experimental metastasis of human melanoma cells in athymic nude mice. Cancer Res 66 : 6699-6707, 2006. 